\title{
Abortion: Still Unfinished Agenda in Nepal
}

\author{
Dirgha Raj Shrestha, ${ }^{1}$ Shibesh Chandra Regmi, ${ }^{1}$ Ganesh Dangal ${ }^{2}$ \\ ${ }^{1}$ Ipas-Nepal, Kupondole, Lalitpur, Nepal, '2Department of Obstetrics and Gynecology, Kathmandu Model \\ Hospital, Exhibition Road, Kathmandu, Nepal.
}

\begin{abstract}
Unsafe abortion is affecting a lot, in health, socio-economic and health care cost of many countries. Despite invention of simple technology and scientifically approved safe abortion methods, women and girls are still using unsafe abortion practices. Since 2002, Nepal has achieved remarkable progress in developing policies, guidelines, task shifting, training human resources and increasing access to services. However, more than half of abortion in Nepal are performed clandestinely by untrained or unapproved providers or induced by pregnant woman herself. Knowledge on legalization and availability of safe abortion service among women is still very poor. Stigma on abortion still persists among community people, service providers, managers, and policy makers. Access to safe abortion, especially in remote and rural areas, is still far behind as compared to their peers from urban areas. The existing law is not revised in the spirit of current Constitution of Nepal and rights-based approach. The existence of abortion stigma and the shifting of the government structure from unitary system to federalism in absence of a complete clarity on how the safe abortion service gets integrated into the local government structure might create challenge to sustain existing developments. There is, therefore, a need for all stakeholders to make a lot of efforts and allocate adequate resources to sustain current achievements and ensure improvements in creating a supportive social environment for women and girls so that they will be able to make informed decisions and access to safe abortion service in any circumstances.

Keywords: Abortion; safe abortion service;stigmatization.
\end{abstract}

\section{INTRODUCTION}

Unsafe Abortion has been identified as one of the major public health problems by World Health Organization (WHO) and international conferences like International Conference on Population and Development (ICPD) and Women's Conference in Beijing. ${ }^{1-3}$ To solve the problem of unsafe abortion, simple technologies, such as manual vacuum aspiration and medical abortion drugs have been developed and these technologies of safe abortion services (SAS)are possible to provide even by periphery level health workers like auxiliary nurse midwife (ANM), and staff nurse. ${ }^{4}$ These procedures are proven as safe and effective methods, when the health workers perform these using standard guidelines and protocols.

Despite recent advancement in SAS, 25 million unsafe abortions (45\% of total abortion-56 million each year), occurred every year between 2010 and 2014. Among them, about one out of three (31\%) of abortion were "less safe". These are provided either by a trained provider but performing unsafe practices (e.g. Dilation and Curettage) or by an untrained person providing recommended medical abortion pills. About one out of seven (14\%) were "least safe" abortions performed under highly risky traditional methods (e.g. inserting sharp iron or object inside the vagina, or mixture of locally available herbs). ${ }^{5}$ Among the total unsafe abortion cases, the majority $(97 \%)$ are performed in developing countries. ${ }^{6}$ Persisting such a high number of unsafe abortion, leads to a high burden of complications; maternal death; and substantial costs to women, families, and health systems.

Due to consequences of unsafe abortion, about five million women and girls are admitted in hospitals each year to treat abortion-related complications. This problem leaves 220,000 children motherless. These risks depend on the types of facilities where abortion is carried out; knowledge and skills of the providers, types of techniques used, the health status of the woman, and the gestational age. ${ }^{7}$ The consequences of unsafe abortion affect not only the individual women and their family members, but also the society, and the nation sincethe already limited health budget has to be diverted to care for abortion complications.

Correspondence: Dirgha Raj Shrestha, Ipas-Nepal, Kupondole, Lalitpur, Nepal. Email: shresthadr@ipas.org, Phone: +9779851074163. 
PROGRESSES IN SAFE ABORTION SERVICES (SAS) IN NEPAL

In Nepal, efforts to liberalize the abortion law began in the 1970s. Finally, the Government of Nepal amended the Nepal Criminal Code (Muluki Ain) in 2002. The current law allows abortion to perform under the request and consent of the woman:up to 12 weeks of gestation for any indication, up to 18 weeks of gestation in the cases of rape and incest, and at any time during pregnancy, if mental/physical health or life of the pregnant woman is at risk or if the fetus is deformed and incompatible with life.

After liberalization of law, following achievements have been made in Nepal:

Development of Policies, Strategies and Guidelines The Government of Nepal (GoN)is keen in developing different policies and guidelines to start and expand SAS in the country. After amendment of law, the GoN developed National Safe Abortion Policy and Procedure Order in 2003. Similarly, Medical Abortion Scale Up Strategy, National Safe Abortion Service Implementation Guidelines, and MADrug and Equipment Supply Guidelines were developed respectively in 2008, 2011 and 2013. Just recently in 2018, the existing SAS implementation guidelines have been revised to incorporate the free safe abortion policy and address barriers in the program.

\begin{tabular}{|ll}
\hline Milestones of Abortion Program in Nepal. \\
\hline 2002 & Legalization of abortion \\
\hline 2003 & $\begin{array}{l}\text { Developed National Safe Abortion Policy and } \\
\text { Procedure Order }\end{array}$ \\
\hline 2004 & $\begin{array}{l}\text { Started the first legal abortion services in } \\
\text { Kathmandu }\end{array}$ \\
\hline 2006 & $\begin{array}{l}\text { Piloted and started CAC service by Staff } \\
\text { Nurses }\end{array}$ \\
\hline 2007 & $\begin{array}{l}\text { Started Second Trimester Safe Abortion } \\
\text { Services }\end{array}$ \\
\hline 2008 & $\begin{array}{l}\text { Mifepristone and Misoprostol registered by } \\
\text { Department of Drug Administration }\end{array}$ \\
\hline 2009 & $\begin{array}{l}\text { Piloted and started Medical Abortion service } \\
\text { by SBA trained ANMs }\end{array}$ \\
\hline 2011 & $\begin{array}{l}\text { Developed National Safe Abortion Service } \\
\text { Implementation Guidelines }\end{array}$ \\
\hline 2013 & $\begin{array}{l}\text { Developed MA Drugs and Equipment Supply } \\
\text { Guidelines } \\
\text { Started “Free Safe Abortion Service” in } \\
\text { government health facilities }\end{array}$ \\
\hline 2016 & \\
\hline
\end{tabular}

Strengthening Service Delivery

Safe abortion service was first started in Paropakar Maternity and Women's Hospital, Kathmandu in 2004 after conducting Trainers of Training (TOT) on Manual Vacuum Aspiration (MVA) for twenty senior gynecologists. Within slightly more than one-year period, as of August 2005, 87 health institutions (53 government and 34 private and non-governmental) were approved for providing comprehensive abortion care services. These 87 institutions were located in 49 out of 75 districts of the country. ${ }^{8}$ Despite rapid expansion, comprehensive abortion care services remain out of reach for many women, particularly those living in rural and remote areas. The GoN thus piloted a program on provision of MVA service through staff nurses in 2006. To increase service further near to rural community and being based on the international evidence about the safety and efficacy of Medical Abortion (MA), "MA Scale-Up Strategy and Implementation Guideline" was developed in 2009 and MA service provisionwas piloted accordingly. ${ }^{9}$ As of now, MA service has been expanded in 51 districts of Nepal at selected PHCs and HPs. Safe abortion service after 12 weeks or also called as Second Trimester Service was also initiated in 2007 and is now available in 29 hospitals.

\section{Training}

Training is an important part of the quality of SAS, to initiate which, National Health Training Center (NHTC) under the Ministry of Health $(\mathrm{MoH})$ and in collaboration with Ipas Nepal, developed the curriculum based on the international evidences. A total of 20 trainers took part in TOT of first safe abortion in 2003 and these trainers conducted subsequent training programs. At present, NHTC has developed training manuals for Second Trimester SAS, Comprehensive Abortion Care (CAC) and Medical Abortion service. These curricula are regularly updated based on the international and national evidences and experiences. There are nine training sites in the government sector and some in non-government sector as well to conduct safe abortion training. After 2003, more than 3,000 different cadres of health care providers have been trained under NHTC.

\section{Expanding Roles of Health Care Workers (Task Shifting) in Safe Abortion Service}

To increase access to safe abortion service and mitigate the shortage of abortion health care providers, the $\mathrm{GoN} / \mathrm{MoH}$ piloted and expanded SAS gradually from Obstetrician/ Gynecologist to ANMs. As in most of the developing countries, there is a critical shortage of trained health workers especially in rural areas of Nepal despite the bitter reality that the people living in these areas have greater need of basic health services like safe abortion and contraception. Nepal is known as 
one of the successful countries to provide safe abortion service up to community level through task shifting mechanism. ${ }^{10}$ However, the demand for services is still not adequately met.

\section{Knowledge of Women and Girls on SAS}

Acquiring knowledge is the first step in the behavior change process. Without adequate knowledge, behavior does not sustain or continue. So, in any health-related program, different activities are implemented to increase knowledge of target groups. Consequently, the $\mathrm{MoH}$ and the other partner organizations are implementing various Social Norms and Behavior Change (SBC) activities to increase knowledge on safe abortion, including its legal conditions. However, the recent NDHS $^{11} 2016$ data showed that only 41\% or two in five women aged 15-49 years were aware of the legalization of abortion and only $48 \%$ knew the place where a safe abortion can be obtained. Knowledge is poor among women in rural areas, those with no education, and lowest wealth quintile.

\section{Stigma on Abortion}

Kumar, Hessini and Mitchell proposed a definition ${ }^{12}$ of abortion stigma as: "a negative attribute ascribed to women who seek to terminate a pregnancy that marks them, internally or externally, as inferior to ideals of womanhood."Abortion occurs everywhere during women's reproductive life cycle period, it is perceived as bad and immoral. A study ${ }^{13}$ conducted in 2016 in Makawanpur district of Nepal, the key informants reported that abortion is a correct choice for unwanted pregnancy, although they did not have a positive perception of women who had abortion. Post-abortion women are labeled as: sinner(papini), ill-luck (alichhini), murderer (jyanmaara), and fetus killer (garbhaghati). In some cases the women who had abortion are even prohibited from religious activities. In addition, service providers and spouses of abortive women are also stigmatized and seen as bad persons.

\section{Ownership and Accountability}

Nepal is considered as one of successful countries in safe abortion program especially in the area of developing policies and guidelines, task shifting, and expanding second trimester and MA services at community level. The GoN/MoH has developed free safe abortion policy and allocated budget to execute the services in public health facilities. Safe abortion service is being implemented as part of Reproductive Health $(\mathrm{RH})$ services and provided in hospitals, primary health care centers and health posts.
Recording, reporting and logistics supply system are managed as per the government's Health Management Information System and Logistics Management System, respectively.

\section{CHALLENGES AND ISSUES}

Despite a remarkable progress in safe abortion services in Nepal, there is still a lot of space to improves the demand for and access to safe abortion services. Unsafe abortion practices are still highly prevalent especially in remote and rural areas. ${ }^{14}$ Women are still in the jail as they are convicted of abortion and infanticide. Some of the challenges and issues in safe abortion program in Nepal are as follows:

\section{Poor knowledge on Safe Abortion}

Despite one and half decade of successful safe abortion program in Nepal, knowledge of women on legal condition is still very poor. According to NDHS 2016,still three-fifths (59\%) of the women of reproductive age group do not know that abortion has been legalized in Nepal. Similarly, slightly more than half (52\%) do not know about a place where safe abortion service is available. It is noteworthy to mention here that the level of knowledge in 2011 was 38\% and it increased only by $3 \%$ during the five years period. This result tells us that there is a lot to be done to increase the knowledge of women and girls in the country. Interestingly, women who did not know that abortion was legal were more likely to seek abortion information from pharmacists than those who knew abortion was legal. ${ }^{15}$ Apparently, it will be too naive to expect from these women with poor knowledge in this are that they will practice safe abortion.

\section{Prevalence of Unsafe Abortion}

The main aim of safe abortion program is to reduce the unsafe abortion so that it can minimize the deaths and complications occurring due to unsafe abortion practices. However, a study ${ }^{16}$ conducted in 2014 revealed that an estimated 323,000 abortions were annually performed in Nepal, which translates to a rate of 42 abortions per 1000 women aged 15-49. Nationwide, more than half abortion (58\%) were clandestine procedures provided by untrained or unapproved providers or induced by the pregnant woman herself. ${ }^{16}$

\section{Limited Facilities}

Safe abortion service was started in Nepal in 2004 and was expanded in all 75 district hospitals and selected Primary Health Care (PHC) Center by 2009. ${ }^{17}$ Similarly, 
MA abortion through trained Skilled Birth Attendance ANMs was introduced in 2009 and it has been expanded in 51 districts by the end of 2017. Second Trimester SAS were started in 2007 and it has been expanded in 29 hospitals by the end of 2017. However, the access to service is still limited. Only about one out of ten (13.6\%) and one quarter $(25.9 \%)$ of health facilities in Nepal provide Comprehensive Abortion Care (CAC) and Medical Abortion only respectively among the facilities offering normal delivery services. ${ }^{18}$ The access to all types of safe abortion services in remote, rural and mountainous areas remains a challenge.

\section{Abortion Stigma}

Stigma among women, community members, service providers and policy makers contributes to the use of unsafe abortion practices. One of the main reasons that women cannot access to safe abortion services is its stigmatization. Different studies have shown that abortion is badly stigmatized in Nepal and it exists at all levels. Although the GoN permitted to perform abortion in certain conditions in 2002, some policy makers and health managers still carry negative perception of this service and thus have been resisting to facilitate safe abortion trainings, provide services and allocate budget as needed. At times, it is the individual's interest that is obstructing the safe abortion services rather than the government policy as such.

\section{Law, Policy and Guidelines}

The new Constitution of Nepal 2015 has adopted reproductive health as fundamental rights of women. But the legalization of abortion is still under the criminal act. It means, it is not fully considered as women's fundamental rights. Similarly, the Nepal Health Sector Strategy $2015-2020^{19}$ has not included safe abortion service as basic health service package although it was included as part of Essential Health Care Service Package in Nepal Health Sector Program II 2010-2015. ${ }^{20}$ As per the current policy and guidelines of $\mathrm{MoH}$, service providers and health facilities should be certified and approved by Family Health Division before they start providing safe abortion services. This policy is fine as long as the task of issuing certificates and listing the health service facilities is done on time. However, the delays in this activity can compel the women and girls seeking safe abortion service to look for unsafe abortion practices as what has been experienced from nearly the three-fifths (58\%) of the abortion services being clandestine nature as discussed earlier

\section{Sustainability}

The GoN/MoH has been supporting to increase access to safe abortion services despite limited resources. However, the existence of abortion stigma and the shifting of the government structure from unitary system to federalism in absence of a complete clarity on how the safe abortion service gets integrated into the local government structure might create challenge to sustain these developments. It is important for the $\mathrm{MoH}$ to ensure that the policies and guidelines developed as of now are all implemented in the same spirit at provincial and local levels as well. There is a huge demand for resources to establish the basic infrastructure in all provinces. In this scenario, there can be a challenge in allocating budget for abortion program in the coming days.

\section{High Unintended Pregnancy}

Unintended pregnancy is one of the major causes of induced abortions. Unintended pregnancy can occur due to non-use of contraception, or from contraceptive failure. A majority of unintended pregnancies result from contraceptive failure. ${ }^{22} \mathrm{About}$ one-fifth of pregnancies $(19 \%)$ is unintended in Nepal $(12 \%$ were mistimed, and $7 \%$ were unwanted). ${ }^{11}$ However, some other studies claim that half of pregnancies are unintended in Nepal. ${ }^{16}$ There is no data about the burden of unintended pregnancy on the family, society and the entire nation due to contraceptive failure. Correct use of contraceptive depends on the educational level of users, quality of counseling and types and suitability of methods recommended. In Nepal, low use of modern methods, high rate of the use of traditional methods as well as temporary methods like condom, pills and depo-provera, low level of literacy, and weak counseling have been the reasons for contraceptive failure.

Low Use of FP and Limited Access to Long Acting Reversible Contraception (LARC)

The use of family planning methods has a strong relationship with abortion. The date from a crosssectional analysis of 18 countries showed a very high negative correlation between abortion and the use of modern contraceptive methods. In two-thirds of the countries, contraceptive failure accounted for most abortions, while in the remaining one-third countries, unmet need for family planning contributed to most of the abortions. Many studies ${ }^{14,23}$ showed that the use of 
effective modern contraception reduces unintended pregnancies and abortions.In Nepal, use of modern contraceptive is stagnated for the last ten years. Although there is an increasing trend in the use of traditional methods, the use of LARC methods is limited. The GoN/ MoH, has planned to increase users' access to all types of temporary family planning methods in the health facilities by ensuring their availability as per the user's choice, only 43 percent of health facilities offer all five temporary methods. As a result of the failure of contraceptives and low use of family planning methods, there has been an increase in unintended pregnancies implying the need for safe abortion.

\section{Irrational and Unregistered Drugs Dispensing through Medical Shops}

According to the policy of the GoN/ MoH Nepal, over the-counter sale of MA drugs by medical shops and providing services by untrained health practitioners and unregistered health facilities are not permitted. However, registered or unregistered MA pills are easily available at majority of medical shops. The Department of Drug Administration under the $\mathrm{MoH}$ has approved only four types of MA drugs (Medabon, MTP Kit, Mistol, and Pregno), however, a study conducted in two eastern districts of Nepal revealed that medical shops were selling 18 different brands of mifepristone and misoprostol tablets. ${ }^{24}$

\section{CONCLUSIONS}

United Nations, together with its member countries, have envisioned "No one be left behind" in all over the world by 2030, as part of the Sustainable Development Goals (SDGs). Similarly, the Constitution of Nepal 2015 has endorsed Reproductive Health as women's fundamental human rights. As part of SDGs, government has also committed to reduce maternal mortality, achieve universal access to sexual and reproductive health, information, education and services, and gender equality. Provision of safe and legal abortion is one of the essential components to fulfill the SDGs. Nepal has achieved remarkable progress in access to safe abortion during the last one and half decades, despite the political instability, shifting of government priorities during the post-conflict situation and limited resources, both capital and trained human resources. However, there are many challenges that still need to be addressed to fulfill the demand for safe abortion services and ensure reproductive rights of women and girls. The access to safe abortion services, especially in hard to reach areas, is still a far cry. There are still thousands women visiting hospitals with complications arouse from unsafe abortions, the use of ineffective or risky methods suggested by uncertified service providers and health facilities. Abortion stigma existsat all levels and is hindering to manage, sustain, provide and receive quality services. The existing safe abortion law is still under criminal act and is not revised as per the spirit of the new constitution and women's human rights perspectives. To strengthen quality safe abortion service and ensure reproductive rights of women and girls in Nepal, there is further need to expand the safe abortion services in rural and remote areas, implement effective SBC activities aiming to increase knowledge on safe abortion provisions and reduce stigma, advocate to pass the Comprehensive $\mathrm{RH}$ Bill to realize that safe abortion is basic rights of women, develop new strategies to streamline safe abortion services through private clinics, and undertake regular monitoring at service sites. To prevent unintended pregnancies the $\mathrm{MoH}$ must strengthen program to increase access and use of informed choice of contraceptive methods and provide comprehensive sexuality education to general population,especially adolescents. Government and non-governmental organizations need to work together to implement the safe abortion programs effectively and make the best and the efficient use of limited resources. Nepal needs to make some strenuous efforts in terms of passing the RH Bill, allocating adequate capital resources, addressing abortion stigma, and increasing the number of trained human resources and certified service facilities to complete the unfinished agenda of effective safe abortion in the country.

\section{REFERENCES}

1. World Health Organization. Twentieth World Health Assembly. Geneva: World Health Organization Geneva; 1967.[Full Text]

2. United Nations. Report on the International Conference on Population and Development, Cairo, September 5-13, 1994. New York: United Nations, Department of Economic and Social Affairs, Population Division; 1994. [Full Text]

3. United Nations. Beijing deceleration and Platform of action. In Fourth World Conference on Women, Beijing, September 4-15, 1995. New York: United Nations; 1995. [Full Text]

4. World Health Organization. Health workers roles in providing safe abortion care and post abortion contraception. Geneva: World Health Organization; 2015.[Full Text] 
5. Ganatra B, Gerdts C, Rossier C, Johnson Jr BR, Tunçalp Ö, Assifi A, etal. Global, regional, and subregional classification of abortions by safety, 2010-14: estimates from a Bayesian hierarchical model. Lancet. 2017;390(10110):2372-81. [Full Text]

6. WHO and Guttmacher Institute. Worldwide, an estimated 25 million unsafe abortions occur each year.Geneva: Joint news release WHO/Guttmacher Institute; 2017. Full Text]

7. Haddad LB, Nour NM. Unsafe abortion: unnecessary maternal mortality. Rev Obstet Gynecol. 2009;2(2):122 6. [Link]

8. Tamang A, Tamang J. Availability and Acceptability of Medical Abortion in Nepal: Health Care Providers' Perspectives. Reprod Health Matters. 2005;13(26):1109.[Full Text]

9. KC NP, Basnett I, Sharma SK, Bhusal CL, Parajuli RR, Andersen KL.Increasing Access to Safe Abortion Services Through Auxiliary Nurse Midwives Trained as Skilled Birth Attendants. Kathmandu Univ Med J. 2011;36(4):260-6. [Full Text]

10. United Nations. ICPD Beyond 2014 Expert Meeting on Women's Health: Rights, Empowerment and Social Determinants, New York, 30th September - 2nd October, 2013, Mexico City.[Full Text]

11. Ministry of Health, Nepal, New ERA, and ICF. Nepal Demographic and Health Survey 2016. Kathmandu: Ministry of Health, Nepal, New ERA, and ICF; 2017. [Full Text]

12. LeTourneau K. Abortion stigma around the world: A synthesis of the qualitative literature. A technical report for members of The International Network for the Reduction of Abortion Discrimination and Stigma (inroads). Chapel Hill, NC: Inroads; 2016.[Full Text]

13. Beyond Beijing Committee. Abortion Stigma and its Effect on Women in Nepal. Buddhanagar, Kathmandu, Nepal. June 2016.[Full Text]

14. BhandariTR, Dangal G. Abortion Practices in Nepal: What does Evidence Show? NJOG. 2015;10(19);3-11.[Full Text][DOI]
15. Rocca CH, Puri M, Dulal B, Bajracharya L, Harper CC, Blum M, et al. Unsafe abortion after legalisation in Nepal: a cross-sectional study of women presenting to hospitals. BJOG. 2013;120:1075-84.[Full Text]

16. CREHPA andGuttmacher Institute. Abortion and Unintended Pregnancy in Nepal. Katmandu, Nepal: CREHPA; 2017.[Full Text]

17. Samandari G, Wolf M, Basnett I, Hyman A, Andersen K. Implementation of legal abortion in Nepal: a model for rapid scale-up of high quality care. Reprod Health. 2012;9(7):1742-55.[Full Text]

18. Ministry of Health, Nepal; New ERA, Nepal; Nepal Health Sector Support Program (NHSSP); and ICF. Nepal Health Facility Survey 2015. Kathmandu, Nepal: Ministry of Health; 2017.[Full Text]

19. Government of Nepal, Ministry of Health. Nepal Health Sector Strategy, 2015-2020. Kathmandu, Nepal: Ministry of Health; 2015.[Full Text]

20. Government of Nepal, Ministry of Health and Population, Nepal Health Sector Programme, 2010-2015.Kathmandu, Nepal: Ministry of Health; 2010.[Full Text]

21. Bradley SEK, Croft TN,Rutstein SO. The Impact of Contraceptive Failure on Unintended Births and Induced Abortions: Estimates and Strategies for Reduction. DHS Analytical Studies No. 22. Calverton, Maryland, USA: ICF Macro; 2011.[Full Text]

22. Westoff CF. Recent Trends in Abortion and Contraception in 12 Countries. DHS Analytical Studies No. 8. Calverton, Maryland: ORC Macro; 2005[Full Text] .

23. Center for Population, Health and Nutrition. Family Planning Prevents Abortion, POP Brief. Washington: USAID: 2001.[Full Text]

24. Tamang A, Puri M,Lama K, Shrestha P. Pharmacy worker in Nepal can provide the correct information about using mifepristone and misoprostol to women seeking medication to induce abortion. Reprod Health Matters. 2015; Supplement (44):104-5.[Full Text] 